\title{
Modeling of Energy-saving System of Conditioning Mine Air for Shallow Underground Mines
}

\author{
Alexandr Nikolaev ${ }^{1 *}$, Timur Miftakhov ${ }^{2}$, Evgeniya Nikolaeva ${ }^{3}$ \\ ${ }^{1}$ Perm National Research Polytechnic University, Department of Mining Electrical Engineering, 29 \\ Komsomolsky prospect, Perm, 614990, Russian Federation \\ ${ }^{2}$ Saint-Petersburg Mining University, Department of Electroenergetics and Electromechanics, 21 Line, \\ 2, St. Petersburg, 199106, Russian Federation \\ ${ }^{3}$ T.F. Gorbachev Kuzbass State Technical University, Department of Mathematics, 650000, 28 \\ Vesennyaya St., Kemerovo, Russia
}

\begin{abstract}
Mines of Verkhnekamsk potassium-magnesium salt deposit in Perm Krai can be subsumed under shallow mines (depth less than 500 meters). At the present moment in shallow underground mines the are problem of condensate formation in large quantities, when ventilation warm seasons of the year. This problem is more actual for salt mine, where during contact between water and potassium-magnesium ore produced electrolyte, which give rise wear of equipment. For prevent/quantity reduction condensate formation in mine used system of conditioning (refrigerating and dehumidifying) mine air (ACS). However, application this system is limited by reason of tremendous costs of electric energy for their work.
\end{abstract}

\section{Introduction}

Famously climatic conditions of mine weather in salt mines are of interest from the point of view of: evaluating their effects on the state of health and working capacity of miners; dynamics of dust content in mine atmosphere; works of ventilation structures. In addition climatic conditions of mine weather in salt mines can be of interest from the point of view of effects of moisture precipitation in the warm season in underground mining workings, because of hygroscopicity, solubility adjacent stratas and mineral product. System of conditioning (refrigerating and dehumidifying) mine air (ACS) can be used on mines for improve sanitation and hygiene standards of works by miners and increase security depth of mining in salt mine [1, 2 et al.]. Herewith the supplied air in ACS must be go through the process of dehumidification, because if relative air humidity $80 \%$ and more there is an effect of secondary condensate formation (moisture precipitation is not only in field and in-seam workings of mine, but also in air shaft, because decrease temperature therein [3].

The issue about the use of system of conditioning mine air (ACS) is more actual for under shallow salt mines (depth is less than or equal to 500 meters). This is due to the following reasons. Rock temperature in field and in-seam workings of mine is practically unchanged

\footnotetext{
*Corresponding author: nikolaev0811@mail.ru
} 
during lifetime of mine. The value of temperature air supplied to mine in warm season is often far higher than the value of rock temperature. For example, rock temperature in Mines of Verkhnekamsk potassium-magnesium salt deposit is $7-11^{\circ} \mathrm{C}$, at the same time the average temperature of air supplied to mine is $21,5{ }^{\circ} \mathrm{C}$ with relative humidity of $92 \%$ to $95 \%$ [3]. Moreover, during the motion in air shaft the temperature of air increases by a few degrees (approximately $1{ }^{\circ} \mathrm{C} / 100$ meters) by reason of rising barometric pressure $[2,4]$.

Surface system of conditioning mine air is not applicable in under deep mines (deep is more than or equal to 500 meters), because rock temperature is close to or sometimes higher than temperature of air supplied to mine. At such mining companies for mine-air refrigerating in particular areas mainly used spot air conditioners are located in work places of field and in-seam workings of mine [4]. In this case the problem of moisture precipitation is absent because of heating process (incoming cold air from mine rocks) happens at a constant humidity content $[2,4]$.

If in under shallow mines ACS is absent then during heat exchange process of air moisture begins accumulating in mines. It happens because value of temperature air supplied to mine is more than the value of rock temperature and also because reducing the relative humidity of air in result his refrigeration. Moisture precipitation may lead to consequences such as: water-flooding a mine workings; pillars disintegration; slip of conveyor belt (with the possibility of burning) etc. In salt mines during contact between moisture and potassiummagnesium ore produced electrolyte which give rise wear of equipment.

However, the use of system of conditioning mine air (ACS) is limited by reason of tremendous cost to electric energy for work these systems. According to the data [5] maintenance cost of surface ACS reach $0,76 \mathrm{mln}$ EURO/year for $1 \mathrm{MW}$ the cooling capacity of the installation.

\section{Theory}

Authors in patent «RU 140553 Ventilation system at under shallow mine» offers method of conditioning mine air for under shallow mines. This method allows increase energy efficiency of air handling process in warm season. In the proposed method air supplied to intake shaft 1 and 2 must be cooled and drained in surface-underground system of conditioning air (Figure 1). Air-cooler (evaporator) 4 of surface ACS located in surface complex 4 of intake shaft №1, but evaporator of underground ACS located in shaft inset 6 of intake shaft №2. Due to work of main mine ventilation fan (MMVF) 10 located in surface complex of MMVF 11 cooled air enters in blind workings 7 (field and in-seam workings without the way to the surface) and removed through main airways 8 on the air shaft 9 to the surface.

The air is cooled in evaporators, because of refrigerant (refrigerant vapour) circulates in heat-exchange tubes. Refrigerant vapour give the cold to air - is heated and transferred to liquid form. After that heated refrigerantis cooled by condensers.

The heated refrigerant vapour in evaporators of surface and underground ACS comes in condensers 14 and 15 through the pipeline 12, which located in breakthrough 13. Refrigerant vapour is cooled in condensers 14 and 15, because cooling ventilators is working. Air door 16 is located in breakthrough 13 for prevent short-circuiting of air stream between intake shaft 2 and air shaft 9. In result the heated air 17 flows from condensers 14 and 15 to main airways 8 and further in air shaft 9 . If there are difficulties associated with laying of pipeline with refrigerant 12 from evaporator of surface ACS, condensers of underground ACS 15 will be only installed in main airways 8 .

You must consider that thermal drops of ventilation pressure (natural drafts) $h_{\text {ni }}$ (Figure 1) operate between mine shafts during the ventilation of mine. Natural drafts occur in results of convection heat transfer, ie when more warm (more easy) air seeks to rise above, while 
more cold (more heavy) air seeks to descend down [5-8]. Thermal depressions occur between communicated shafts. Thermal depressions is cause of drops in hydrostatical pressure in shafts and prevent or to help motion of air. Combined action of thermal depressions forms resulting natural draft of mine $\left(\mathrm{h}_{\mathrm{ni}}\right)$. The resulting natural draft of mine influences the mode of main mine ventilation fan (MMVF) depending on direction. The resulting natural draft can either increase or decrease the total air volume supplied to mine. The mode of main mine ventilation fan can be switched to area of less pressures if resulting natural draft is positive. In this case, reduced electric power consumption [2]. You need to consider difference in height grades of shaft mouths and surface leakages of air in shaft house when choosing the regulation mode of main mine ventilation fan subject to the resulting natural draft of mine [9].

The location option of surface and underground ACS is shown in Figure 1. Bleeding of warm air issued from condenser of ACS will increase the value of positive resulting natural draft of mine. This, in turn, will contribute to the reduction of electric power costs for work of ACS [2].

\section{Results and discussions}

The purpose of this paper is derivation of mathematical functions which allow to choose parameters of underground ACS and determine the effect of this method on the energy efficiency of air handling.

Need to determine the refrigerating power ( $\mathrm{q}_{\mathrm{c} . \mathrm{s}}$ ) of underground ACS, when choosing an evaporator for underground ACS. The refrigerating power depends on the necessary value of cooling temperature of air in mine working $\mathrm{T}_{\mathrm{a}}$. For determine the refrigerating power $\left(\mathrm{q}_{\mathrm{c} . \mathrm{s}}\right)$ can then be used a formula: $[10,11]$ :

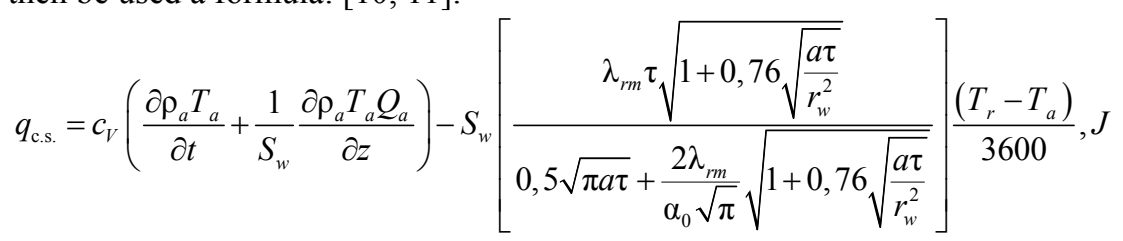

where $c_{V}$ - specific heat capacity of air at constant volume, $\mathrm{J} / \mathrm{kg} \cdot{ }^{0} \mathrm{C} ; \rho_{\mathrm{a}}(t, z)$ - air density in working the necessary value of cooling temperature of air $T_{\mathrm{a}}, \mathrm{kg} /$ cubic meter; $S_{\mathrm{B}}-$ crosssectional area of working, square meter; $Q_{\mathrm{a}}$ - required capacity of evaporator, cubic meter/sec.; $\lambda_{\mathrm{rm}}$ - thermal conductivity coefficient of rock massif, $\mathrm{J} / \mathrm{kg} \cdot$ hour $\cdot{ }^{0} \mathrm{C} ; \tau-$ time since the start of the installation, hour; $a$ - thermal diffusivity coefficient of rock massif, square meter/hour; $\alpha_{0}$ - heat transfer coefficient (total), J/square meter hour ${ }^{\circ} \mathrm{C} ; r_{\mathrm{B}}-$ equivalent radius of working, the value of which can be found as $r_{w}=\sqrt{\frac{S_{w}}{\pi}}$, meter; $T_{\mathrm{r}}$-temperature of non-refrigerated mine rocks (see Figure 2).

Cool air temperature must be less than or equal to temperature of non-refrigerated mine rocks $\left(T_{\mathrm{a}} \leq T_{\mathrm{r}}\right)$ in order to ensure that moisture does not fall out on rock massif walls of field and in-seam workings.

Also in this method the possibility of secondary condensate formation is excluded, because of bleeding of warm air issued from condensers of underground and/or surface ACS (heating temperature of air supplied in air shaft is higher than dew point temperature) $[2,3]$.

Thus, the value $T_{\mathrm{a}}$ will be determined depending on the magnitude of temperature of nonrefrigerated mine rocks $T_{\mathrm{r}}$. According to [4] $T_{\mathrm{a}}$ depends from such parameters as: depth of mine $\left(H_{\mathrm{m}}\right)$, temperature of neutral zone $\left(T_{\text {n.z. }}\right)$ and stratification depth of neutral zone $\left(H_{\text {n.z. }}\right)$, geothermic gradient $(\sigma)$ : 


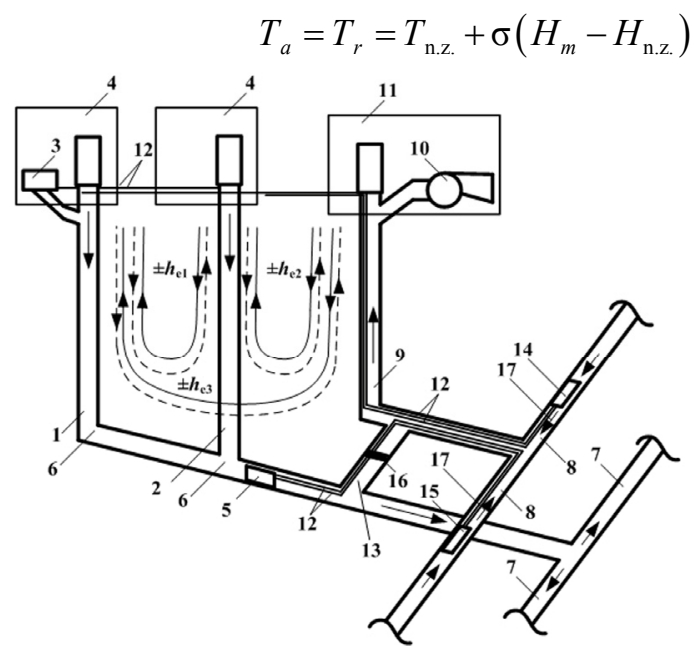

Fig. 1. Simplified scheme of mine ventilation and location of ACS : 1 - intake shaft № 1;2 - intake shaft № 2;3 - evaporator (air-cooler) of surface ACS; 4 - surface complexes of intake shafts; air supplied in mine; 5 - evaporator (air-cooler) of underground ACS; 6 - shaft inset of intake shaft; 7 field and in-seam workings without the way to the surface; 8 - main airways; 9 - airshaft; 10 - main mine ventilation fan (MMVF); 11 - surface complex of MMVF; 12 - pipeline with refrigerant; 13 breakthrough; 14 - condenser of surface ACS; 15 - condenser of underground ACS;16 - air door; 17 - air heated in condensers 14 and 15

However, keep in mind the fact that in field and in-seam workings without the way to the surface 7 in addition to air cooled in evaporator of underground ACS, air will be flown from intake shaft № 1 and №2. This air will be heated during the descent on shaft. The heated air from intake shaft №1 will be flown in shaft inset of intake shaft 6 , in evaporator 5 and workings 7. Part of the air supplied on intake shaft №2 will go on workings without the way to the surface past the evaporator 5 (Figure 1).

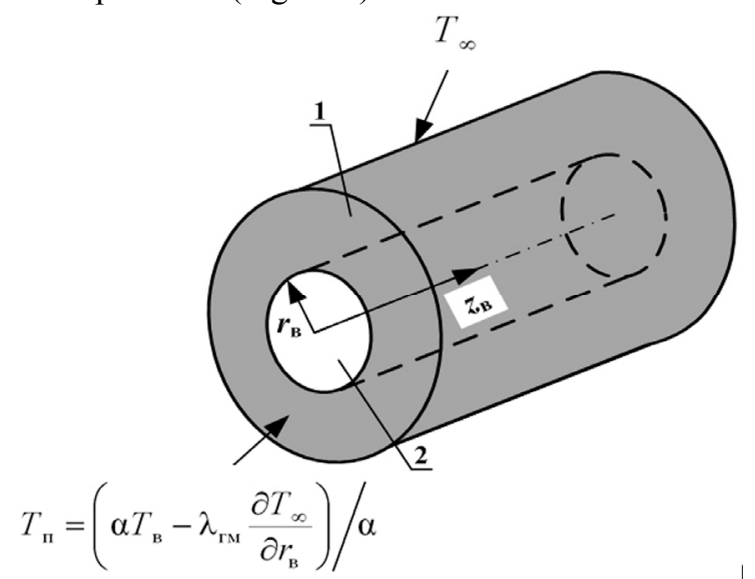

Fig. 2. Scheme to determine the amount of heat emitted from rock massif: 1 - rock massif; 2 - mine working with equivalent radius $r_{\mathrm{w}} ; \alpha$ - heat transfer coefficient between mine air and rock massif; $T_{\infty}-$ temperature of mine rocks on removal from the location of rock massif

According to the output from the formulas of paper [2] the required evaporator capacity of underground ACS can be determined by the formula

$$
Q_{a}=\frac{Q_{p} \rho_{p} I_{p}-Q_{s 1} \rho_{1} I_{1}-Q_{s 2} \rho_{2} I_{2}}{\rho_{a} I_{a}}
$$


where $Q_{\mathrm{p}}, Q_{\mathrm{s} 1}, Q_{\mathrm{s} 2}$ - air-flow rates by air, which enters accordingly in field and in-seam workings without the way to the surface, intake shafts №1 and №2, cubic meter/sec.; $\rho_{\mathrm{p}}, \rho_{1}$, $\rho_{2}$ - density of the air, which enters accordingly in accordingly in field and in-seam workings without the way to the surface, in shaft insets of intake shafts №1 and №2, kg/ cubic meter; $I_{\mathrm{p}}, I_{1}, I_{2}$ - specific enthalpy of air, which enters accordingly in accordingly in field and inseam workings without the way to the surface, in shaft insets of intake shafts №1 and №2, $\mathrm{kJ} / \mathrm{kg} ; I_{\mathrm{a}}-$ specific enthalpy of air on output of ACS, when the value $T_{\mathrm{a}}$ is required

If the values of temperature are known then the density of air in the i-th point can be defined according to the well-known formula:

$$
\rho_{i}=\frac{0,465 P_{i}}{273,15+T_{i}}
$$

According to [9] barometric pressure and temperature of air in shaft insets of intake shafts can be found by the formulas:

$$
\begin{aligned}
& P_{i . s .}=a_{1} \cdot P_{a}^{n_{1}}+a_{2} \cdot T_{s h}^{n_{2}}+a_{3} \cdot H_{s h}^{n_{3}}+a_{4} \cdot D_{s h}^{n_{4}}+a_{5} \cdot Q_{s h}^{n_{5}} \\
& T_{i . s .}=a_{1}^{\prime} \cdot P_{a}^{n_{1}^{\prime}}+a_{2}^{\prime} \cdot T_{s h}^{n^{\prime}{ }_{2}}+a_{3}^{\prime} \cdot H_{s h}^{n_{3}^{\prime}}+a_{4}^{\prime} \cdot D_{s h}^{n_{4}{ }_{4}}+a^{\prime}{ }_{5} \cdot Q_{s h}^{n_{5}^{\prime}},
\end{aligned}
$$

where $a_{i}, a^{\prime}{ }_{i}, b_{i}$ and $b^{\prime}{ }_{i}-$ regression coefficients [9]; $n_{i}, n^{\prime}{ }_{i}, m_{i}$ и $m^{\prime}{ }_{i}$ - the degree of the parameter [9]; $T_{\mathrm{sh}}, H_{\mathrm{sh}}, D_{\mathrm{sh}}$ and $Q_{\mathrm{sh}}$ - accordingly temperature of air, which enters in intake shaft $\left({ }^{\circ} \mathrm{C}\right)$, depth (meter), diameter (meter) of intake shaft and volume of air, which enters in intake shaft, cubic meter/sec.

It should be noted that in formulas (5) and (6) for intake shaft for the value $T_{\text {sh }}$ taken air temperature after mixing flows of atmospheric and cooled in evaporator of surface ACS

According to [4] specific enthalpy in the i-th point can be defined by the formula:

$$
I_{i}=1,005 T_{i}+\left(2500+1,8 T_{i}\right) \frac{d_{i}}{1000}
$$

where $d_{i}$ - temperature $\left({ }^{0} \mathrm{C}\right)$ and moisture content $(\mathrm{g} / \mathrm{kg})$ of air in the $\mathrm{i}$-th point.

According to [4] moisture content of air in the i-th point can be found by the formula:

$$
d_{i}=623 \frac{\phi_{i} P_{\text {t.p. }}}{P_{i}-\phi_{i} P_{\text {t.p. }}}
$$

where $\varphi_{i}$ - relative air humidity air in the i-th point; $P_{\text {t.p. }}-$ partial pressure of water vapor at the total saturation (millimeter of mercury).

Note that the evaporator of underground ACS will work as installation with ejection: when air stream on output of underground ACS revealed at a certain angle $\theta$ and fills all drift size. It's like a work of pneumatic piston (Figure 3).

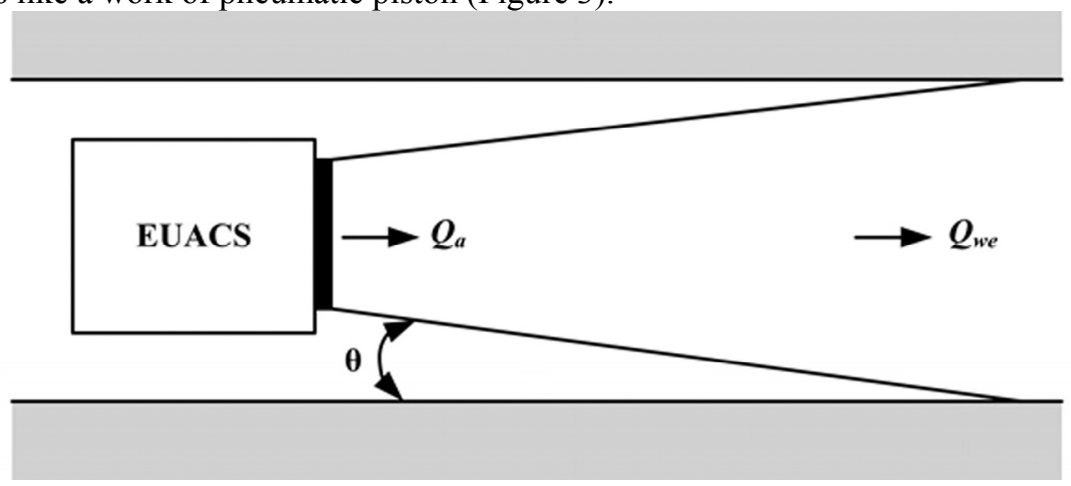

Fig. 3. Disclosure of air stream (process of ejection) on output from evaporator of underground ACS (EUACS) 


\section{Conclusions}

1. The described method of conditioning the air will allow to cool mine air to a temperature of rocks. In result will decrease electric power costs for work of ACS.

2. The bleeding of warm air in the air shaft will allow to exclude possibility of occurrence of secondary condensation in it. Also the process of bleeding warm air in the air shaft will contribute to a observances resulting positive natural draught in mine (thermal depression). As a result in mine will flow more air. In this case, the mode of operation MMVF can be switched to an area of lower pressure. The electric power costs for work of MMVF will be decrease.

3. According to the above order of calculation you can select the required capacity of the evaporator fans and condensers of underground and/or surface of ACS and evolving process of ejection, which increases the total air volume in the working. For work installations also need less electricity.

In the course of calculations it is established that the proposed system will pay off (considering the modern prices for equipment and electricity) for $3.5-4$ years (on the example of the mine BKPRU-2 of PAO "Uralkali").

Taking the above into account in the implementation of conditioning mine air by the proposed method significantly reduce the cost of electricity for operation of ACS and MMVF. In the mine will stop (significantly reduced) the process moisture precipitation and associated with them the negative and dangerous phenomenon. Held, in the course of mathematical modeling in Solidworks software package flow simulation, research have a high convergence with the results obtained analytically.

\section{References}

1. M.J. McPherson, G. Robinson, Mine vent. South Africa, 33, 145 (1980)

2. A.V. Nikolaev, Gornyi Journal, no. 3, 71 (2017)

3. S. Knothe, B. Nowak, M. Szlazak, Arch. Gorn, 31, 289 (1986)

4. S.G. Gendler, Eurasian Mining, 2, 41 (2016).

5. G.B. Lyal'kina, A.V. Nikolaev, Journal of Mining Science, 51, 342 (2015)

6. W.E. Bruce, Natural draft: its measurement and modeling in underground mine ventilation systems (US: Dept. of Labor, Mine Safety and Health Administr., 1986)

7. P.F. Linden, Annual Review of Fluid Mechanics, 31, 201 (1999)

8. Jianwei Cheng, Yan $\mathrm{Wu}$, Haiming Xu, Jin Liu, Yekang Yang, Huangjun Deng, Yi Wang, Tunneling and Underground Space Technology, 45, 166 (2015)

9. N.I. Alymenko, A.V. Nikolaev, Journal of Mining Science, 47, 636 (2011)

10. L.Yu. Levin, M.A. Semin, A.V. Zaitsev, Journal of Mining Science, 50, 371 (2014)

11. B.P. Kazakov, A.V. Shalimov, M.A. Semin, International Journal of Heat and Mass Transfer, 86, 288 (2015)

12. A. Shadrina, L. Saruev, International Journal of Mining Science and Technology, 24(2), 245 (2014) 